1. Eliyahu M. Goldratt. (1998) Late Night Discussions on the Theory of Constraints. ISBN 0-88427160-9.

2. Бурцев Ю.А., Романченко Л.Н. Процесс обеспечения экономической безопасности предприятия//Успехи современной науки и образования. - 2017. - № 4. - С. $72-75$.

3. Mullakhmetov, K. S., Aminova, R. M., \& Akhmetshin, E. M. (2014). Control in a management system in modern conditions. Asian Social Science, 10(24), 237-247. http://dx.doi.org/10.5539/ass.v10n24p237

4. Татаровский Ю.А., Татаровская Т.Е. Анализ развития малых и средних производственных предприятий в системе экономической безопасности региона // РИСК: Ресурсы, информация, снабжение, конкуренция. 2018. № 4. С. 130-133.

5. Маняева В.А., Пискунов В.А., Фомин В.П., Носков В.А. Учетная политика для целей обеспечения экономической безопасности коммерческой организации // Вестник Самарского государственного экономического университета. 2017. № 8 (154). С. 76-84.

\title{
RISK MANAGEMENT IN THE ENTERPRISE 'S ECONOMIC SECURITY SYSTEM
}

\author{
(C) 2020 Tatarovskaya Tatyana Evgenyevna \\ Candidate of Economics, Associate Professor \\ Samara State University of Economics \\ E-mail: tatarovskaya.tatyana@gmail.com
}

Keywords: economic security, enterprises, risks, risk appetite, risk optimization, risk management, risk-oriented approach.

The article is devoted to the use of a risk-based approach in the enterprise's economic security system implementation. The author proposes an algorithm for risk management within the framework of the economic security system, as well as considers possible areas of risk management. The study identified the main risks inherent in the activities of domestic trading enterprises.

УДК 338.2

Код РИНЦ 06.00.00

\section{СИСТЕМА СБАЛАНСИРОВАННЫХ ПОКАЗАТЕЛЕЙ В ЭКОНОМИЧЕСКОЙ БЕЗОПАСНОСТИ ПРЕДПРИЯТИЯ}

\author{
() 2020 Татаровский Юрий Алексеевич \\ кандидат экономических наук, доцент \\ Самарский государственный экономический университет \\ E-mail: tatarovsky.yury@yandex.ru
}

Ключевые слова: система сбалансированных показателей, экономическая безопасность, предприятие, финансовая устойчивость, дью дилидженс, хороший баланс, бизнес-процесс. 
Статья посвящена использованию системы сбалансированных показателей при реализации системы экономической безопасности предприятия. Автором рассмотрено внедрение концепции системы сбалансированных показателей сквозь призму следующих составляющих: финансовая составляющая, контрагенты, кадры, внутренние бизнес-процессы. Для целей использования каждой составляющей предложены количественные индикаторы.

Сбалансированная система показателей (далее - ССП) является важным инструментом для разработки и реализации стратегических управленческих решений. Несмотря на активное развитие и ее применение на зарубежных предприятиях, в России она нуждается в дальнейшем развитии из-за необходимости повышения производительности и эффеетивности работы со стороны как регулирующих органов, так и бизнеса. Таким образом, адаптация данной концепции для отечественных коммерческих организаций имеет большое теоретическое и практическое значение, как для их деятельности в общем, так и для обеспечения их экономической безопасности, в частности.

Основным элементом в формировании системы ССП экономической безопасности (далее - ЭБ) является разработка стратегического подхода к обеспечению и управлению экономической безопасностью, а также его выражение через конкретные показатели.

В рамках концепции ССП не предложены методические основы либо рекомендации по формированию систем сбалансированных показателей. Однако, основным моментом в реализации концепции ССП является ее компактность, то есть каждая группа должна содержать не более 3-4 показателей.

Рассмотрим детально каждую из составляющих ССП ЭБ хозяйствующего субъекта.

І. Финансовая составляющая.

Стратегическая цель финансовой составляющей ССП ЭБ предприятия заключается в повышении финансовой устойчивости и финансовой результативности. В качестве ключевого показателя возможно использовать показатель финансовой устойчивости определяемого как эффективное формирование, распределение, и использование финансовых ресурсов, обеспечивающее развитие предприятия на основе роста прибыли, капитала и сохранения платежеспособности при сбалансированном привлечении заемных ресурсов (см. таблицу).

Перечень показателей финансовой составляющей ССП ЭБ

\begin{tabular}{|l|c|}
\hline \multicolumn{1}{|c|}{ Показатель } & Рекомендуемое значение \\
\hline Коэффрициент автономии & $\mathrm{K}_{\text {авт }} \geq 0,5$ \\
\hline Рентабельность продаж & - \\
\hline Коэфффициент общей платежеспособности & $\mathrm{K}_{\text {оп }}>2$ \\
\hline Коэффрициент абсолютной ликвидности & $\mathrm{K}_{\text {ал }}>0,2$ \\
\hline
\end{tabular}

Представленный в таблице перечень показателей, состоит из основных коэффициентов, наиболее полно и всесторонне описывающих финансовый аспект обеспечения экономической безопасности предприятия с имеющимся рекомендуемым значением, которое может также принимать индивидуальную оценку'.

II. Составляющая контрагентов ССП ЭБ. 
Составляющая качества контрагентов ССП ЭБ, в отличии от традиционно выделяемой клиентской составляющей, шире и включает в себя не только анализ канала сбыта, но и качества снабжения. В то же время, ключевые показатели, характеризующие составляющую контрагентов ССП ЭБ, направлены на оценку, в первую очередь, качества дебиторов и состояния дебиторской задолженности, как параметров, способных привести к техническому банкротству предприятия. Таким образом, в основе показателей составляющей контрагентов ССП ЭБ лежит показатель оборачиваемости дебиторской задолженности, и доля просроченной дебиторской задолженности в общем объеме дебиторской задолженности.

В современной практике можно встретить множество методик качественной оценки надежности контрагентов, куда можно отнести и процедуру Дью Дилидженс, рекомендации ФНС России по реализации принципа должной осмотрительности налогоплательщика и др².

Также целесообразно проводить оценку имущественного положения контрагента. Одной из самых эффективных с позиции соотношения информационной полезности и затрат на проведение аналитических процедур является проверка на соблюдение признаков "хорошего" баланса. Данная методика предполагает 6 пунктов проверки, характеризующих основные изменения параметров деятельности всего предприятия. Так, возможно предложить следующую интегральную оценку качества контрагента, основанную на соблюдении критериев "хорошего" баланса:

- Высокая, при соблюдении всех шести критериев.

- Нормальная, при соблюдении не менее двух критериев.

- Низкая (кризисная), при несоблюдении более трех критериев.

Таким образом, составляющая контрагентов ССП ЭБ позволяет не только повысить интенсивность использования ресурсов предприятия (вложенных в дебиторскую задолженность), избежать финнансовых потерь, но также противодействовать налоговым и деловым рискам³.

III. Кадровая составляющая ССП ЭБ.

Составляющая использования трудовых ресурсов (кадровая составляющая ССП ЭБ) основывается на трех ключевых показателях, характеризующих конечный результат использования трудовых ресурсов, а также показатели их движения:

- Коэффицциент выбытия трудовых ресурсов;

- Коэффициент обновления трудовых ресурсов;

- Выработка на одного работающего.

Сокращение коэффициента выбытия свидетельствует о том, что предприятие сохраняет свой кадровый потенциал, а профессиональный уровень ее сотрудников увеличивается. В то же время, привлечение дополнительных сотрудников свидетельствует о развитии масштаба деятельности предприятия, что в совокупности с увеличением выработки свидетельствует о положительном развитии данной составляющей ССП ЭБ4. Также стоит отметить, что снижение текучести кадров является важным элементом, обеспечивающим экономическую безопасность предприятия, так как: 
- Сокращаются издержки на обучение новых сотрудников до уровня выбывших трудовых ресурсов, что позволяет инвестировать в повышение квалификации персонала для повышения эффективности его функционирования.

- Минимизируются риски экономической безопасности, связанные с разглашением информации, содержащей коммерческую тайну, уволившимися сотрудниками.

- Высокий профессионализм сотрудников, позволяет не только обеспечить эффективность основных бизнес-процессов и высокое качество выпускаемой продукции, но и сократить издержки функционирования, с помощью эффректа "кривой опыта".

Показатель выработки на одного работающего характеризует производительность труда на предприятии, что является ключевым показателем, описывающим качество использования трудовых ресурсов 5 .

IV. Составляющая внутренних бизнес-процессов ССП ЭБ.

Составляющая внутренних процессов ССП ЭБ направлена на противодействие основным рискам, присущим конкретной деятельности и характеризуется эффрективным функционированием системы внутреннего контроля, которая может оцениваться с помощью следующих параметров:

- Наличие на предприятии системы внутреннего контроля;

- Разработка мер по контролю за сохранностью документов и защите коммерческой тайны;

- Проведение мониторинга конкурирующих компаний;

- Разработка системы по противодействию коррупции на предприятии.

Эффеективность функционирования составляющей бизнес-процессов ССП ЭБ во многом зависит от систематического характера ее применения, так как она призвана выявлять недостатки и возможные риски, а также способствовать их своевременному устранению. Для этого предприятию необходимо регулярно проводить анализ составляющей рисков, содержащихся во внутренних бизнес-процессах компании.

1 Фомин, В. П. Формирование и анализ показателей финансового состояния организации // Международный бухгалтерский учет. 2016. № 6. С. 2-8.

2 Яркина Н.Н. Прикладные аспекты совершенствования управления финансовым риском в контексте обеспечения экономической безопасности предприятия // Вестник Самарского государственного экономического университета. 2019. № 2 (172). С. 79-88.

3 Корнеева Т.А., Наумова О.А., Светкина И.А. Организационные аспекты обеспечения экономической безопасности крупной розничной торговли (ритейл) // Вестник Самарского государственного экономического университета. 2017. № 155. С. 69-79.

4 Гильфанов М.Т. Организационно-методический инструментарий оценки детерминантов и обеспечения экономической безопасности организации//Социально-экономические явления и процессы. 2013. № 8 (054). С. 19-27.

5 Хафизова А.Р. Совершенствование сбалансированной системы показателей как эффективный инструмент стратегического управления организацией // Вестник современных исследований. 2018. № 8.2 (23). С. 94-96. 


\title{
SYSTEM OF BALANCED INDICATORS IN THE ECONOMIC SECURITY OF THE ENTERPRISE
}

\author{
(C) 2020 Tatarovskij Yury Alekseevich \\ Candidate of Economics, Associate Professor \\ Samara State University of Economics \\ E-mail: tatarovsky.yury@yandex.ru
}

Keywords: balanced scorecard, economic security, businesses, financial stability, due diligence, good balance, business process.

The article is devoted to the use of a system of balanced indicators in the implementation of the enterprise's economic security system. The author considers the implementation of the balanced scorecard concept through the prism of the following components: financial component, contractors, personnel, internal business processes. Quantitative indicators were proposed for using each component.

УДК 004, 336

Код РИНЦ 06.00.00

\section{РАЗВИТИЕ ЦИФРОВОЙ ЭКОНОМИКИ В БАНКОВСКОМ СЕКТОРЕ НА ПРИМЕРЕ БЛОКЧЕЙНА}

\author{
() 2020 Тимофеева Арина Юрьевна \\ студент \\ Самарский государственный университет \\ E-mail: arina_tim007@mail.ru
}

Ключевые слова: цифровая экономика, "сквозные" технологии, блокчейн, смарт-контракты, криптовалюта, "Мастерчейн".

Сегодня экономику можно классифицировать как цифровую экономику, так как почти все операции в банковской сфере проводятся онлайн. Именно поэтому в данной статье рассматривается сущность блокчейна и его развитие в российской экономике.

Цифровая экономика так или иначе касается всех сфрер жизни общества. Однако именно банки являются основными проводниками "сквозных" технологий в индустрию финансовых услуг. Создается особая система, которая полностью изменяет функционирование банковского сектора, например, теперь множество операций происходят в online-режиме, что позволяет быстро проводить безналичные платежи. Таким образом данные услуги становятся более доступными для граждан и организаций. Но с появлением технологий, связанных с сетью Интернет, участились случаи виртуального мошенничества, поэтому гарантировать безопасность данных потребителей может блокчейн, 0 котором пойдет речь в данной статье. 